\title{
Investigation on the Fracturing Permeability Characteristics of Cracked Specimens and the Formation Mechanism of Inrush Channel from Floor
}

\author{
Jianning Wang $\mathbb{D},{ }^{1,2}$ Weitao Liu $\mathbb{D},{ }^{1}$ and Jianjun Shen $\mathbb{D}^{1,3}$ \\ ${ }^{1}$ College of Energy and Mining Engineering, Shandong University of Science and Technology, Qingdao, Shandong 266590, China \\ ${ }^{2}$ Shandong Pengbo Safety \& Environmental Protection Services Limited, Qingdao, Shandong 266590, China \\ ${ }^{3}$ College of Chemical Engineering and Safety, Binzhou University, Binzhou 256600, China
}

Correspondence should be addressed to Weitao Liu; skdlwt@126.com and Jianjun Shen; shenjianjun11987@163.com

Received 1 September 2020; Revised 1 October 2020; Accepted 16 March 2021; Published 5 April 2021

Academic Editor: Shunhua Chen

Copyright ( 2021 Jianning Wang et al. This is an open access article distributed under the Creative Commons Attribution License, which permits unrestricted use, distribution, and reproduction in any medium, provided the original work is properly cited.

To study the fracture characteristics and the permeability change law of the cracked specimens during the complete stress-strain process, a mechanical model was constructed, from which different types of crack initiation angles were obtained. The crack inclination angles under uniaxial compression, confining compression, and confining tension, and the influence of confining pressure and pore water pressure on the crack propagation and permeability of rock mass were investigated and simulated with RFPA-Flow software using prefabricated crack models with crack initiation angles of $30^{\circ}, 45^{\circ}$, and $60^{\circ}$. Furthermore, the formation mechanism of inrush channel from floor was qualitatively analyzed. The results indicated that the theoretical initiation angles of wing cracks, secondary coplanar cracks, and secondary inclined antiwing cracks were found to be $70.53^{\circ}, 0^{\circ}$, and $123.8^{\circ}$, which were consistent with the simulation results. The crack propagation was mainly concentrated at the postpeak stage of the complete stress-strain curve, causing the peak of seepage velocity to lag behind the stress peak. For the case with a constant confining pressure, the rate of crack initiation and propagation to final failure was positively correlated with the internal pore pressure. For the case with a constant water pressure, the speed of crack initiation and propagation to final failure decreased first and then increased as the confining pressure increased. In addition, the longitudinal propagation of wing cracks and the increase in permeability were prone to occur in the low confining pressure zone, which induced the formation of water inrush channels. The research result provides an improved understanding for predicting and preventing water inrush disasters.

\section{Introduction}

There are many geological structures such as cracks, joints, or fault planes of different scales inside the coal floor due to the complex geological conditions of coal fields in China. The existence of these defect structures not only changes the mechanical properties of the rock but also significantly affects the permeability characteristics of the rock $[1,2]$. In particular, the floor water barrier may be damaged by water and mining pressures when coal excavation is carried out above the aquifer, causing the original defects to close, open, propagate or induce new cracks, and produce macroscopic cracks $[3,4]$. This greatly changes the water conductivity of the water barrier and eventually leads to a large amount of uncontrolled water pouring into the empty mining area, causing serious casualties and economic losses to the coalmining industry, and severe damage to the hydrogeological environment [5]. Therefore, studying the propagation and evolution of rock mass cracks and their permeability characteristics is the base for studying the formation of the floor water inrush channels during mining, and it is also the key to correctly understand the mechanism of mine water inrush disasters. [6-8].

Many researchers have investigated the initiation, propagation, and fracture laws of rock mass cracks. Li et al. took I-II compound cracks as the research object and proposed the use of the relationship between the equivalent SIF ratio and the fracture toughness ratio of I and II cracks in 
order to determine the type of crack fracture, based on the theory of linear elasticity [9]. Sai-Hong et al. analyzed the stress state of a single crack in the compression-shear and tensile-shear state and introduced the damage variables in the Dugdale crack model. They deduced the fracture criterion of cracked rock mass considering the effect of water damage under compressive-shear and tensile-shear stress conditions, based on the fracture criterion under compressive-shear conditions and the maximum circumferential stress theory [10]. Brace and Bombolakis conducted a singlecrack uniaxial compression test using photoelastic material and glass to study the fracture characteristics of brittle rock materials, where only wing cracks are found, which is propagated in a curved path and finally paralleled the direction of compression loading, and no secondary cracks appeared [11]. These studies have revealed the shape and path of crack propagation in rock mass to a certain extent and promoted the scientific understanding of crack propagation mechanism. However, the stress condition for the initiation of secondary cracks and the crack initiation angle were rarely discussed in the involved mechanical models.

Zheng-Zhao simulated and studied the failure process of rock specimens with prefabricated three-dimensional surface cracks under uniaxial compression. Further, they discussed the internal force mechanism and propagation law of three-dimensional cracks using RFPA software [12]. YinLong and Lian-Guo implemented a numerical program for simulating rock damage and fracture and seepage evolution process under fluid-solid coupling using COMSOL software and simulated the formation of a coal seam floor "seepage channel" and the evolution process of water inrush catastrophe [13]. Based on the multifield coupling test instrument, Pei-Sen et al. carried out related rock tests under hydromechanical conditions. The results showed that the permeability of rock samples varies approximately with confining pressure in a power function, which is consistent with that of the steady state method [14]. Also, Wen-Bin et al. revealed the negative exponential relation between that the three-dimensional stress, water pressure, and the fracture permeability coefficient [15]. According to Pei-Sen et al., the confining pressure had a significant effect on seepage inhibition, and the variation trend of permeability decreased with the increasing confining pressure [16]. Researchers have also investigated the failure characteristics and fracture modes of cracked rocks and some related problems [4, 17-29]. However, these studies still have not systematically analyzed the fracturing and permeability characteristics of cracked rock masses under different loading conditions. Further, the obtained results lacked the macroscale mechanical analysis for the formation of the postmining floor water channel.

In this paper, a crack propagation mechanical model under compression and shear was established, and the crack initiation angle was theoretically investigated using fracture mechanics theory. A related numerical model was constructed to perform uniaxial compression, confining compression, and confining tension tests. Further, the fracture characteristics and the permeability change law of cracked rock mass, and its relationship with fracture inclination $\beta$, pore water pressure $P$, and confining pressure $\sigma y$ were simulated and studied. The mechanical mechanism for the formation of water inrush channels in the floor unloading zone is qualitatively discussed, which has a certain theoretical significance and practical value for the prevention of water inrush from the mine floor.

\section{Mechanical Analysis of Crack Propagation}

The mechanical analysis of crack propagation includes the mechanical model of crack propagation and initiation criteria for primary and secondary cracks. They are briefly described below.

2.1. Mechanical Model of Crack Propagation. Mechanical models for different types of crack propagation were developed. The typical crack propagation patterns are mainly divided into three types, namely, wing cracks, secondary coplanar cracks, and secondary inclined antiwing cracks (Figure 1) [30]. Among them, the wing crack, which is also called the first-order crack or the main crack, is mainly caused by tension at the tip of the crack. It is characterized by stable propagation along the direction of the maximum compressive stress. The secondary coplanar crack is a kind of shear crack that is coplanar or quasi-coplanar with the prefabricated crack. This initiates and propagates from the tip of the prefabricated crack. The secondary inclined antiwing crack has a certain angle with the prefabricated crack, which is similar to the wing crack. However, the crack initiation and propagation directions are opposite to that of the wing crack. In this work, the initiation angle of the crack is theoretically discussed using the theory of fracture mechanics by combining the existing research results.

Considering that the rock force is mostly a mechanical environment under multidirectional compression, a mechanical model of crack propagation under compression and shear is developed (Figure 1(a)). The model contains a central inclined crack with a length of $2 a$ and is set under axial compression $\sigma 1$ and confining pressure $\sigma 3$. Further, the angle between the crack and the vertical is $\beta$. Different types of cracks may initiate from the tip of the prefabricated crack, propagate, and form new cracks under loading.

According to rock mechanics [31], by taking a two-dimensional plane as an example, the far-field stress expression can be expressed as given in the following:

$$
\left\{\begin{array}{l}
\sigma_{y y}=\sigma_{1} \sin ^{2} \beta+\sigma_{3} \cos ^{2} \beta, \\
\tau_{x y}=\left(\sigma_{1}-\sigma_{3}\right) \sin \beta \cos \beta .
\end{array}\right.
$$

By considering the friction effect that is on the crack surface, the effective shear stress $\tau_{\text {eff }}$ is given as follows:

$$
\begin{aligned}
\tau_{e f f}= & \left(\sigma_{1}-\sigma_{3}\right) \sin \beta \cos \beta-\mu \sigma_{y y}=\left(\sigma_{1}-\sigma_{3}\right) \sin \beta \cos \beta \\
& -\mu\left(\sigma_{1} \sin ^{2} \beta+\sigma_{3} \cos ^{2} \beta\right) .
\end{aligned}
$$

In (2), $\mu$ refers to the friction factor. 

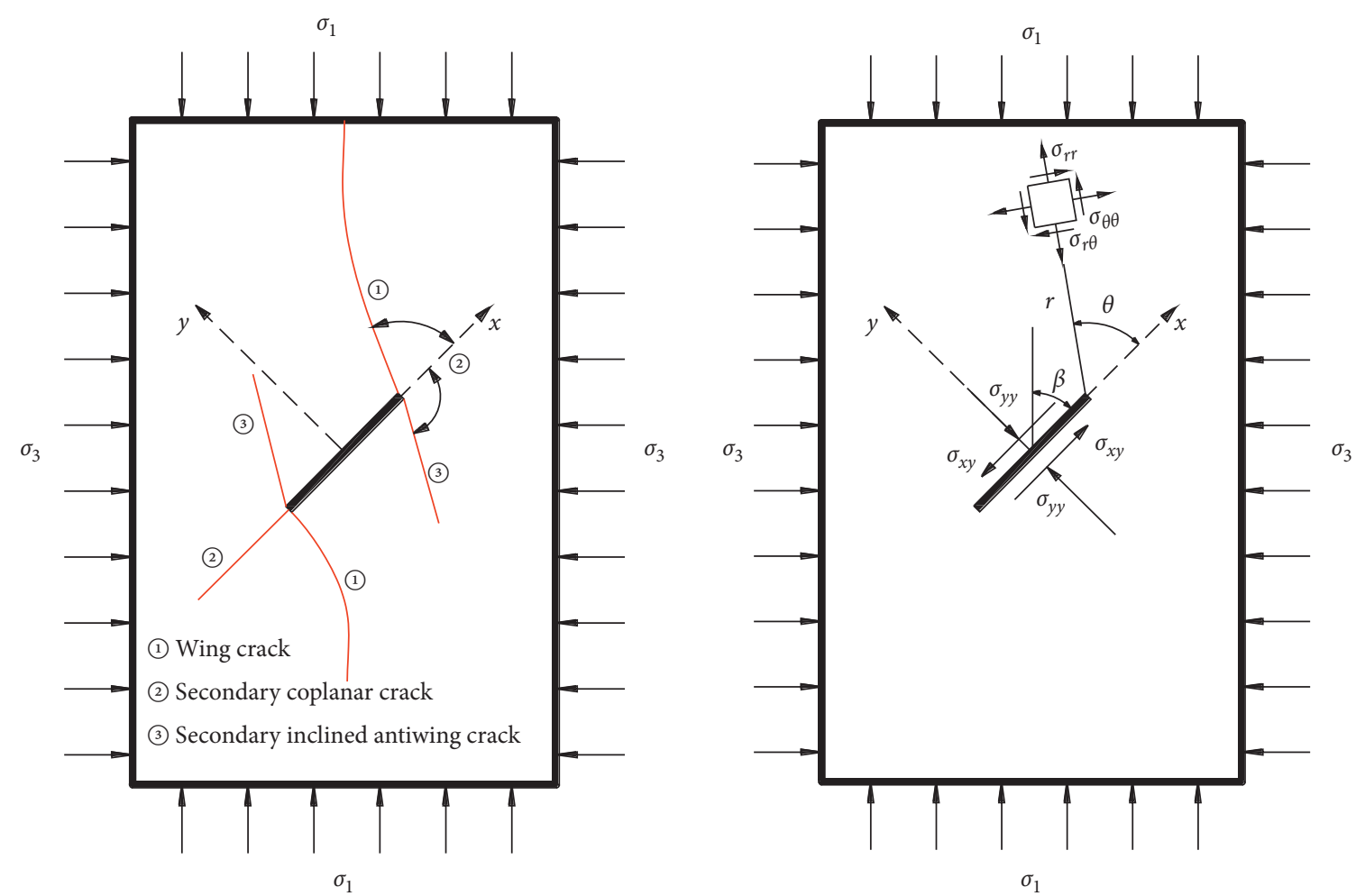

Figure 1: Types of crack propagation and the mechanical model: (a) typical morphology of crack propagation; (b) mechanical mode.

In general, the singular stress field at the tip of a closed crack is still I-II compound type under compression and shear loading [9]. Hence, the stress field at the crack tip can be further expressed by the following:

$$
\left\{\begin{array}{l}
\sigma_{r r}=\frac{1}{2 \sqrt{2 \pi r}}\left[K_{\mathrm{I}} \cos \frac{\theta}{2}(3-\cos \theta)+K_{\mathrm{II}} \sin \frac{\theta}{2}(3 \cos \theta-1)\right], \\
\sigma_{\theta \theta}=\frac{1}{2 \sqrt{2 \pi r}} \cos \frac{\theta}{2}\left[K_{\mathrm{I}}(1+\cos \theta)-3 K_{\mathrm{II}} \sin \theta\right], \\
\sigma_{r \theta}=\frac{1}{2 \sqrt{2 \pi r}} \cos \frac{\theta}{2}\left[K_{\mathrm{I}} \sin \theta+K_{\mathrm{II}}(3 \cos \theta-1)\right] .
\end{array}\right.
$$

In (3), $\theta$ refers to the prepropagation angle of the crack, $r$ refers to the distance between the microunit and the crack tip, and $K_{\mathrm{I}}$ and $K_{\mathrm{II}}$ are the stress intensity factors of type I and type II cracks, respectively.
According to the fracture mechanics theory, the tip stress intensity factor of the inclined crack with the center can be described by the following:

$$
\left\{\begin{array}{l}
K_{\mathrm{I}}=\sigma_{y y} \sqrt{\pi a}=\left(\sigma_{1} \sin ^{2} \beta+\sigma_{3} \cos ^{2} \beta\right) \sqrt{\pi a}, \\
K_{\mathrm{II}}=\tau_{\text {eff }} \sqrt{\pi a}=\left[\left(\sigma_{1}-\sigma_{3}\right) \sin \beta \cos \beta-\mu\left(\sigma_{1} \sin ^{2} \beta+\sigma_{3} \cos ^{2} \beta\right)\right] \sqrt{\pi a} .
\end{array}\right.
$$

2.2. Initiation Criteria for Primary and Secondary Cracks. The initiation criteria for primary and secondary cracks are as follows. The tensile stress appears in the direction of the angle $\theta$ with the crack tip due to the relative slip between the upper and lower surfaces of the crack. It is assumed that the crack propagates along with the angle $\theta$ corresponding to $\sigma_{\theta \max }$, and the maximum circumferential tension criterion is adopted as the primary crack initiation 
criterion. Hence, the crack propagation direction should satisfy the following:

$$
\begin{aligned}
& \left.\frac{\partial \sigma_{\theta \theta}}{\partial \theta}\right|_{\theta=\theta_{0}}=0 \\
& \left.\frac{\partial^{2} \sigma_{\theta}}{\partial \theta^{2}}\right|_{\theta=\theta_{0}}<0 .
\end{aligned}
$$

According to (5), (3) is partially differentiated and it is obtained as follows:

$$
\begin{aligned}
\frac{\partial \sigma_{\theta \theta}}{\partial \theta} & =-\frac{3}{2 \sqrt{2 \pi r}} \cos \frac{\theta}{2}\left[K_{\mathrm{I}} \sin \theta+K_{\mathrm{II}}(3 \cos \theta-1)\right], \\
\frac{\partial^{2} \sigma_{\theta \theta}}{\partial \theta^{2}} & =\frac{3}{4 \sqrt{2 \pi r}}\left\{\frac{1}{2} \sin \frac{\theta}{2}\left[K_{\mathrm{I}} \sin \theta+K_{\mathrm{II}}(3 \cos \theta-1)\right]-\cos \frac{\theta}{2}\left(K_{\mathrm{I}} \cos \theta-3 K_{\mathrm{II}} \sin \theta\right)\right\} .
\end{aligned}
$$

Further, it is simplified and obtained as given in the following:

$$
\cos \frac{\theta}{2}\left[K_{\mathrm{I}} \sin \theta+K_{\mathrm{II}}(3 \cos \theta-1)\right]=0
$$

There are two solutions to (7). When $\cos (\theta / 2)=0$, that is, $\sigma_{\theta}=0, \theta= \pm \pi$, the crack initiation angle cannot satisfy the condition of $\left.\left(\partial^{2} \sigma_{\theta} / \partial \theta^{2}\right)\right|_{\theta=\theta_{0}}<0$ in (5). Hence, the crack initiation angle depends on

$$
K_{\mathrm{I}} \sin \theta+K_{\mathrm{II}}(3 \cos \theta-1)=0 .
$$

The closed crack under compression is considered as pure shear load under compressive load, which implies that $K_{\mathrm{I}}=0$. Then, the crack initiation angle $\theta_{0}$ of the wing crack can be obtained using

$$
\theta_{0}=\cos ^{-1} \frac{1}{3}=70.53^{\circ}
$$

The secondary crack belongs to type II sliding-open crack, which meets the maximum radial shear stress criterion as given in the following equations:

$$
\begin{aligned}
&\left.\frac{\partial \sigma_{r \theta}}{\partial \theta}\right|_{\theta=\theta_{0}}=0, \\
&\left.\frac{\partial^{2} \sigma_{r \theta}}{\partial \theta^{2}}\right|_{\theta=\theta_{0}}<0, \\
& \sin \frac{\theta}{2}=\theta \text { or } 9 \sin ^{2} \frac{\theta}{2}-7=0, \\
& \cos \frac{\theta}{2}\left(\frac{27}{4} \sin ^{2} \frac{\theta}{2}-7\right)>0 .
\end{aligned}
$$

It is obtained that the crack initiation angles $\theta_{0}$ of the secondary cracks are $0^{\circ}$ and $-123.8^{\circ}$, respectively, where the negative value indicates the clockwise direction.

\section{Numerical Simulation}

The RFPA-Flow software is a numerical test tool that is used to simulate the progressive failure of materials. It is also widely used to simulate the failure process and engineering stability of rocks under various loading conditions [25]. Further, it can also simulate the basic seepage characteristics of rocks (body), which considers the impact of seepagestress-damage coupling and the change of permeability during the damage process of the rock mass. Moreover, it adopts the finite element theory and statistical damage theory for calculation. It takes into account the nonuniformity of the material properties and the randomness of defect distribution, which are included in the numerical calculation method (finite element method). It destroys the elements that meet the given strength criterion in order to realize the numerical simulation of the nonuniform material during the failure process.

3.1. Schemes of Numerical Simulations. In this work, the prefabricated single-crack specimen was used as the object, and the relevant numerical model was constructed using RFPA-Flow software. The uniaxial compression, confining compression, and confining tension tests were carried out in order to simulate and study the fracture characteristics and permeability change law of cracked rock mass, and its relationship with fracture inclination angle $\beta$, pore water pressure $P$, and confining pressure $\sigma y$ (Figure 2 ).

The height ( $y$-direction) and width ( $x$-direction) of the numerical model were set to $100 \mathrm{~mm}$ and $50 \mathrm{~mm}$, respectively. Further, the model was divided into $300 \times 150=45000$ element grids with the same shape and size. The length and width of the center crack for the model were taken as $20 \mathrm{~mm}$ and $1 \mathrm{~mm}$, respectively. The displacement load control method was adopted with a displacement load of $2 e-7 \mathrm{~m} /$ step, and plane stress analysis mode was adopted for all models. The calculation obeyed the Mohr-Coulomb strength criterion. 


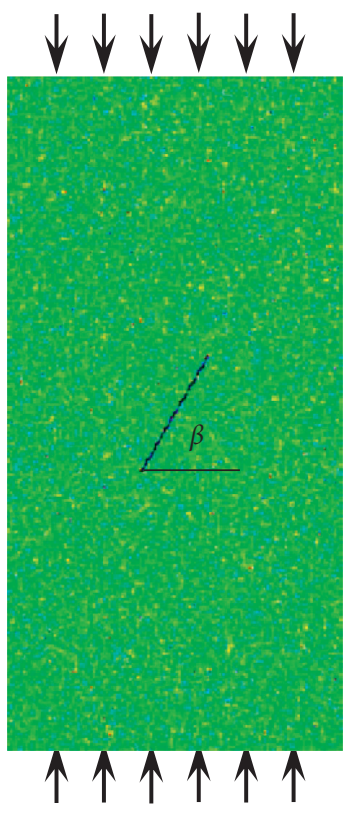

(a)

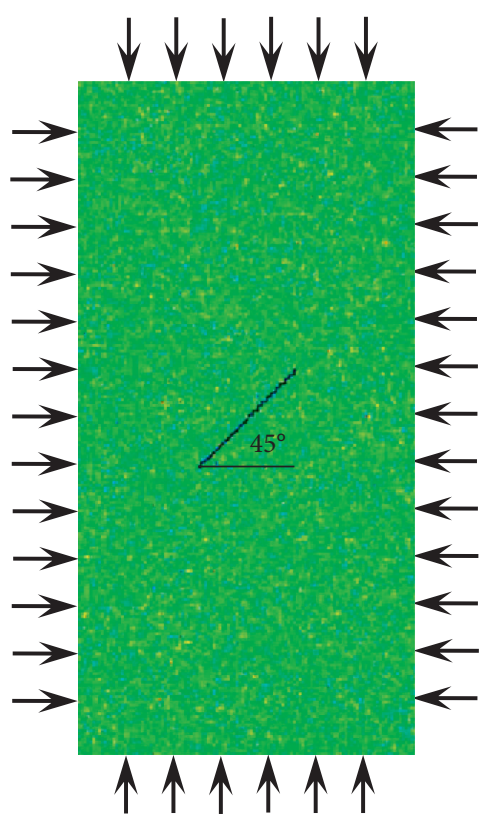

(b)

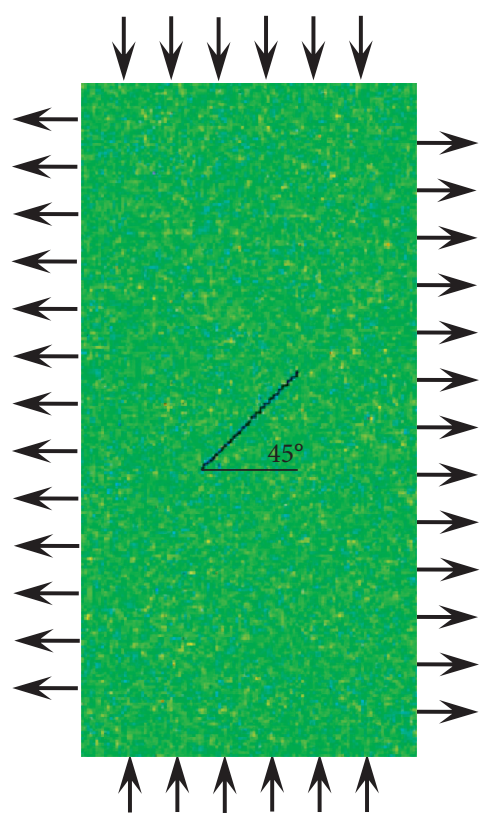

(c)

Figure 2: Loading conditions of numerical models based on the RPFA-Flow software: (a) uniaxial compression; (b) confining compression; (c) confining tension.

The specific numerical test scheme, the physical mechanics, and seepage parameter settings of the model are shown in Tables $1-3$, respectively.

3.2. Simulation Results and Analysis. The simulation and analysis were carried out in order to investigate the evolutions of crack propagation and water pressure under different conditions such as uniaxial compression and confining compression and tension. They are briefed below.

3.2.1. Evolution of Crack Propagation and Water Pressure under Uniaxial Compression. The evolution process of crack propagation and the seepage pore water pressure for models with crack initiation angles of $30^{\circ}, 45^{\circ}$, and $60^{\circ}$ of a single crack under uniaxial compression are shown in Figure 3. From Figure 3, it is observed that when the cracked rock is subjected to mechanical and hydraulic loads, the original defects close, open, and propagate or induce new cracks, thereby changing the structure and the seepage characteristic of the rock [32].

As shown in Figure 3, it is also observed that the growth process of the prefabricated cracks can be divided into four distinct stages, namely, the initial stage (stage 1), the crack initiation stage (stage 2), the stable crack propagation stage (stage 3), and the unstable crack propagation (or piercing instability) stage (stage 4). It is further observed that as the axial load increases, the crack initiates from the tips of the two wings, and the crack initiation direction is at an angle $\theta$ to the crack extension line. Subsequently, the crack propagates approximately in the direction parallel to the axial pressure, gradually propagates to the upper and lower end faces of the specimen, and finally forms a "wing crack" which destabilizes and fails. The evolution of pore water pressure is consistent with the crack propagation process, which implies that the evolution of pore water pressure in the longitudinal direction ( $y$-direction) is greater than that in the transverse direction ( $x$-direction). This not only facilitates the further propagation of the fracture in the fluid-solid coupling process but also easily leads to a significant increase in longitudinal permeability.

Figure 4 shows the relationship between the stress of cracked specimen under uniaxial compression, seepage velocity, number of acoustic emission events, and strain, respectively. It is observed that the stress-strain curves for the model with $30^{\circ}, 45^{\circ}$, and $60^{\circ}$ cracks are basically identical, with obvious compaction stage (A), elastic stage (B), plastic stage $(\mathrm{C})$, and residual load stage (D).

At the early stage of loading which includes compaction stage $A$ and elastic stage $B$, the number of acoustic emission events is less. It is observed that the original cracks are not developed and the overall permeability of the specimen changes marginally. Further, it is also found that the seepage velocity is low. As the loading continues, the plastic failure stage (C) occurs. At this stage, the number of acoustic emission events increases, the cracks begin to initiate and propagate, and the permeability slowly increases. When the stress reaches the peak value, the seepage velocity inside the specimen increases sharply. However, it does not reach the peak value, which indicates that the peak value of permeability lags behind the peak value of stress. Correspondingly, the peak value of the acoustic emission event that represents the failure of the unit appears in the postpeak stage of the stress-strain curve. This indicates that the cracks in the specimen rapidly propagate and form a connected fracture surface during this stage, which induces the permeability to 
TABle 1: The schemes of numerical simulations.

\begin{tabular}{lccc}
\hline & Type & Item & Value \\
\hline \multirow{2}{*}{ Scheme A } & Uniaxial compression & Inclined angle of crack $(\beta)$ & $30^{\circ}, 45^{\circ}, 60^{\circ}$ \\
$0.8 \mathrm{MPa}$ & Pore water pressure $(P)$ & $45^{\circ}$ \\
\hline \multirow{2}{*}{ Scheme B } & & Inclined angle of crack $(\beta)$ & $0.8 \mathrm{MPa}, 1.2 \mathrm{MPa}, 1.5 \mathrm{MPa}$ \\
& Confining compression & Pore water pressure $(P)$ & $2 \mathrm{MPa}, 5 \mathrm{MPa}$ \\
\hline \multirow{3}{*}{ Scheme C } & & Confining pressure $\left(\sigma_{y}\right)$ & $45^{\circ}$ \\
& & Inclined angle of crack $(\beta)$ & $0.8 \mathrm{MPa}, 1.2 \mathrm{MPa}, 1.5 \mathrm{MPa}$ \\
& Confining tension & Pore water pressure $(P)$ & $-2 \mathrm{MPa},-5 \mathrm{MPa}$ \\
\hline
\end{tabular}

TABLE 2: Failure characteristic parameters used in the numerical model.

\begin{tabular}{lc}
\hline Parameter & Value \\
\hline Elastic modulus & $50 \mathrm{GPa}$ \\
Internal friction angle & $30^{\circ}$ \\
Ratio of compression to tension & 10 \\
Compression coefficient & 2001 \\
Tension coefficient & 5 \\
Poisson's ratio & 0.25 \\
Uniaxial compressive strength & $200 \mathrm{MPa}$ \\
Percentage of residual strength & 0.1 \\
Percentage of residual Poisson's ratio & 1.1 \\
Homogeneity & 3 \\
\hline
\end{tabular}

reach the peak value. In the residual load stage (D), the specimen still withstands certain axial stress, and the seepage velocity maintains a high level or continues to increase due to the irreversible formation of macroscopic cracks.

\subsubsection{Evolutions of Crack Propagation and Water Pressure} under Confining Compression and Confining Tension. Figure 5 shows the results of crack propagation obtained using the numerical simulation, where the wing crack and secondary inclined antiwing crack are clearly observed. Further, the initiation angles of the two types of cracks are calibrated. The initiation angle of the wing crack is found to be in the range of $69.8^{\circ}-71.5^{\circ}$, and that of the inclined antiwing crack is approximately $124.3^{\circ}$. These results are consistent with results obtained by the theoretical derivation in which the initiation angles of the wing crack and the secondary inclined antiwing cracks are found as $70.53^{\circ}$ and $123.8^{\circ}$, respectively. Therefore, the numerical simulation results verify the theoretical derivation. The numerically obtained results are roughly consistent with the failure patterns observed in the laboratory testing by Shen et al. [30].

A model with $45^{\circ}$ crack is taken as an example, and the evolution process of crack propagation and seepage pore water pressure under confining compression and confining tension is shown in Figure 6. In the analysis of the crack propagation and permeability under confining compression, it is observed that when the confining pressure $\left(\sigma_{y}\right)$ is constant, the crack initiates and propagates until the final failure rate is positively correlated with its internal pore water pressure $(P)$. When the confining pressure is $2 \mathrm{MPa}$, the main crack propagates vertically to the upper and lower end faces of the specimen in the form of "wing cracks", forming longitudinal macroscopic cracks which are accompanied by the appearance of the secondary inclined antiwing cracks in the direction which is approximately parallel to the axial direction. When the confining pressure is $5 \mathrm{MPa}$, the main crack propagates horizontally to the left and right end faces of the specimen in the form of "antiwing cracks," forming transverse macroscopic cracks. From the results, it is observed that the evolution process of pore water pressure is consistent with crack propagation. Further, the existence of water pressure facilitates crack propagation but does not change the crack shape.

It is further observed that when the water pressure is constant, the crack initiates and propagates until the final failure rate decreases and then increases with the increase of the confining pressure. This indicates that the existence of the confining pressure inhibits the propagation of the crack within a certain range. However, when the confining pressure exceeds a certain value, it can accelerate or facilitate the propagation of cracks.

Figure 7 shows the influence of different factors on the permeability of cracked specimen. From Figure 7(a), it is observed that the axial seepage velocity of the model is proportional to the pore water pressure. This is mainly due to the increase of the cleavage and scouring effect of pore water pressure on the fracture surface as its pressure increases. This causes the opening angel of the formed fracture surface to increase, thereby greatly promoting the permeability of the cracked specimen. Further, from Figure 7(b), it is observed that the axial permeability of the model is inversely proportional to the horizontal confining pressure. This is due to the propagation of the main body of the crack towards the upper and lower end faces of the model with longitudinal wing cracks or accompanied by partial longitudinal antiwing cracks under the action of low confining pressure. This inevitably causes a sharp increase in longitudinal permeability. The main crack propagates towards the left and right end faces of the model with the transverse antiwing cracks when the horizontal confining pressure rises to a high level. This results in greater transverse permeability and lower longitudinal permeability.

From the analysis of the crack propagation and permeability analysis under confining tension, it is observed that the crack propagates in the forms of "wing cracks" and "antiwing cracks" when the confining pressure is $-2 \mathrm{MPa}$. At 
TABLE 3: Seepage parameters used in the numerical model.

\begin{tabular}{lccccccc}
\hline & $\begin{array}{c}\text { Horizontal permeability } \\
\text { coefficient }(\mathrm{m} / \mathrm{d})\end{array}$ & $\begin{array}{c}\text { Vertical permeability } \\
\text { coefficient }(\mathrm{m} / \mathrm{d})\end{array}$ & Porosity & $\begin{array}{c}\text { Pore pressure } \\
\text { coefficient }\end{array}$ & $\begin{array}{c}\text { Damage } \\
\text { mutation coefficient }\end{array}$ & $\begin{array}{c}\text { Separation } \\
\text { coefficient }\end{array}$ & $\begin{array}{c}\text { Coupling } \\
\text { coefficient }\end{array}$ \\
\hline Homogeneity & 100 & 100 & 100 & 100 & 1000 & 1000 & 1000 \\
Average value & 0.000864 & 0.000864 & 0.1 & 1 & 5 & 100 & 0.1 \\
\hline
\end{tabular}

\begin{tabular}{|c|c|c|c|c|}
\hline$\beta^{\text {Stage }}$ & Stage 1 & Stage 2 & Stage 3 & Stage 4 \\
\hline \multicolumn{5}{|l|}{$30^{\circ}$} \\
\hline & Step: $3-1$ & Step: $19-5$ & Step: $22-7$ & Step: $22-27$ \\
\hline \multicolumn{5}{|l|}{$45^{\circ}$} \\
\hline & Step: $3-1$ & Step: $22-2$ & Step: $26-1$ & Step: $26-25$ \\
\hline \multicolumn{5}{|l|}{$60^{\circ}$} \\
\hline & Step: $3-1$ & Step: $38-1$ & Step: $40-10$ & Step: $40-22$ \\
\hline
\end{tabular}

FiguRE 3: Evolution of crack propagation and seepage pore water pressure under uniaxial compression.

the beginning of crack propagation, longitudinal wing cracks form first, and then longitudinal antiwing cracks appear at one end of the original crack. The two propagate in parallel to the upper and lower end faces of the specimen, forming longitudinal macroscopic cracks. When the confining pressure is $-5 \mathrm{MPa}$, the propagation of the wing crack appearing in the early stage is suppressed, and the antiwing crack propagation is mainly in the later stage. The evolution process of pore water pressure is consistent with the crack propagation process, and the longitudinal permeability is greater than the transverse permeability.

\section{Discussion on the Formation Mechanism of Inrush Channel}

Mining coal seam above the confined aquifer inevitably leads to stress redistribution and rock layer destruction, thus triggering water inrush accidents. Li et al. connected the coal seam excavation to the deformation and failure of the floor rock layer with stress, and three obvious failure zones were formed from top to bottom, namely, "mining failure zone," "effective water barrier zone," and "confined water lift zone" [33]. Corresponding to the theoretical results of the "lower three zones," Wang et al. took the coal seam mining above the confined water body of a coal mine in Shanxi province as the engineering background and monitored the horizontal stress distribution in floor strata before and after coal seam mining [34]. Figure 8 shows the failure characteristics and the horizontal stress distribution of the floor after mining. It can be seen that the stress values are roughly divided into three zones, namely, the stress reduction zone (A), confining pressure transition zone (B), low confining pressure zone $(\mathrm{C})$, and high confining pressure zone (D). 


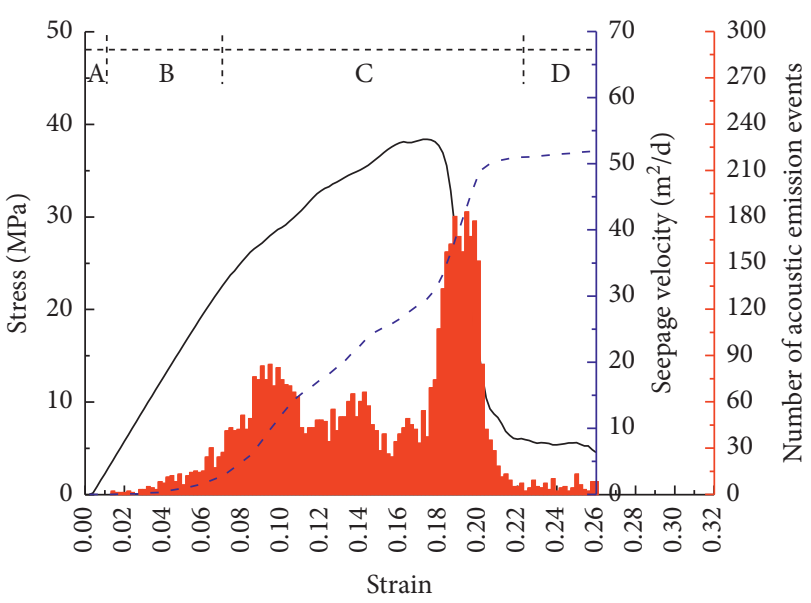

(a)

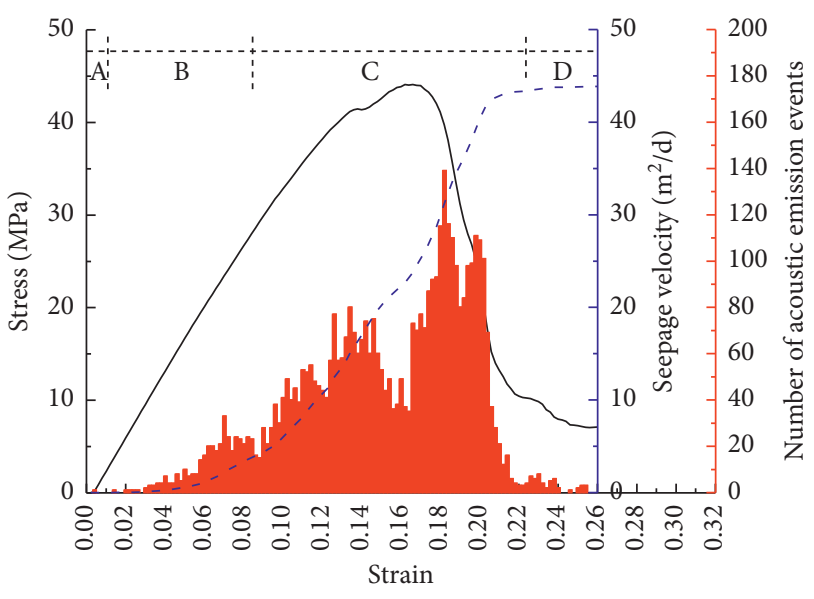

(b)

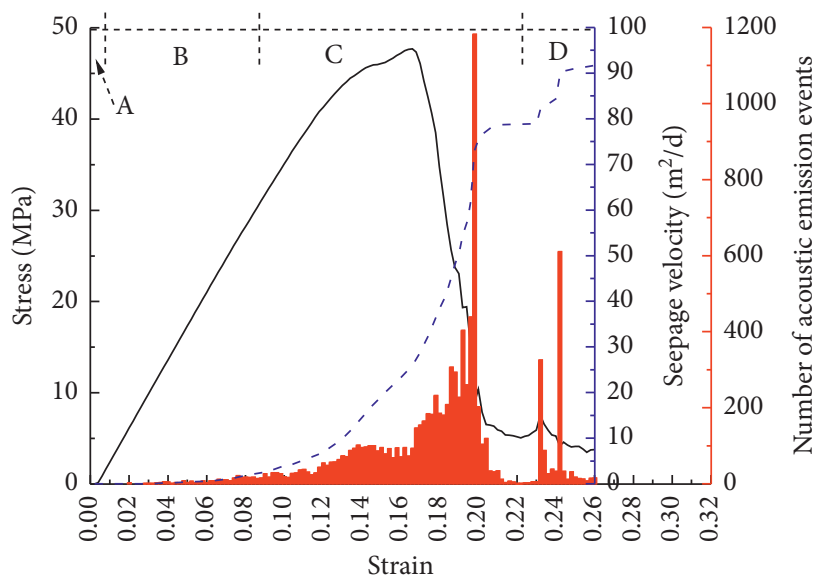

(c)

Figure 4: The relationships of stress, seepage velocity, AE events, and strain of cracked specimens under uniaxial compression. (a) $\beta=30^{\circ}$; (b) $\beta=45^{\circ}$; (c) $\beta=60^{\circ}$.

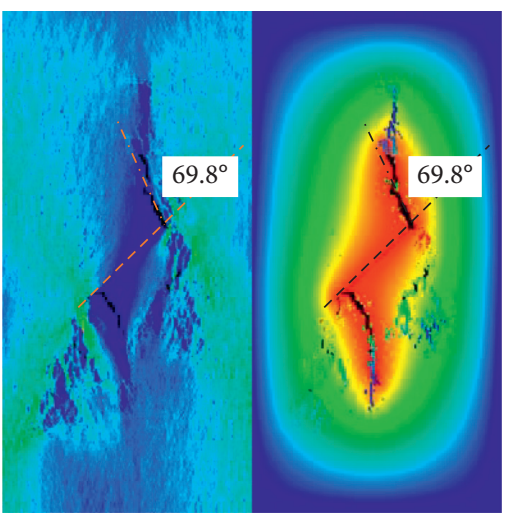

(a)

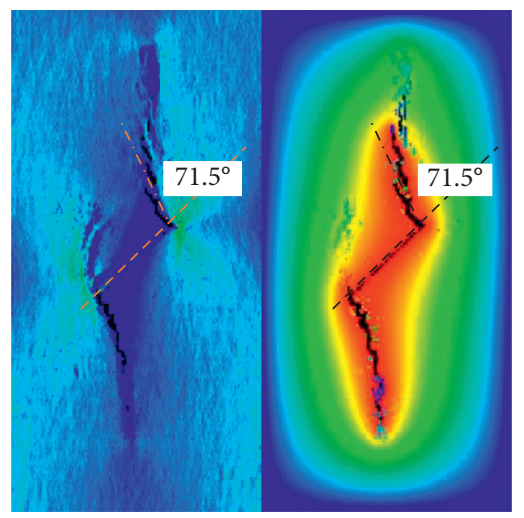

(b)

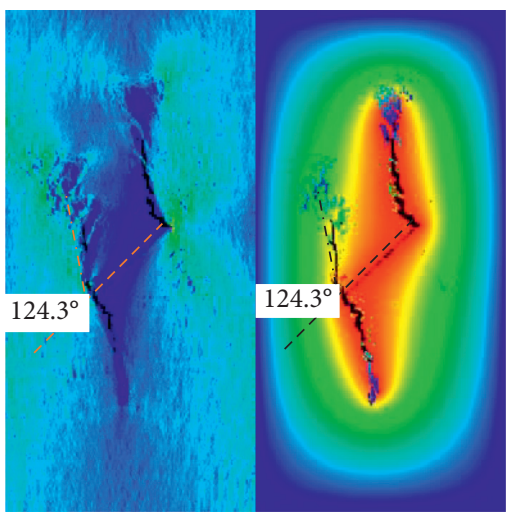

(c)

FIgURE 5: Typical results of crack propagation obtained by numerical simulations (a case with $45^{\circ}$ ).

In the mining failure zone, the floor of the coal seam is severely damaged and the rock mass is relatively broken after mining. The horizontal stress is in a disordered state. The stress is observed to be at the transition zone from high confining pressure to low confining pressure within the effective water barrier layer. In the confined water lift zone, the stress is found to be at a low confining pressure zone. From the results, it is observed that the rock mass in this 


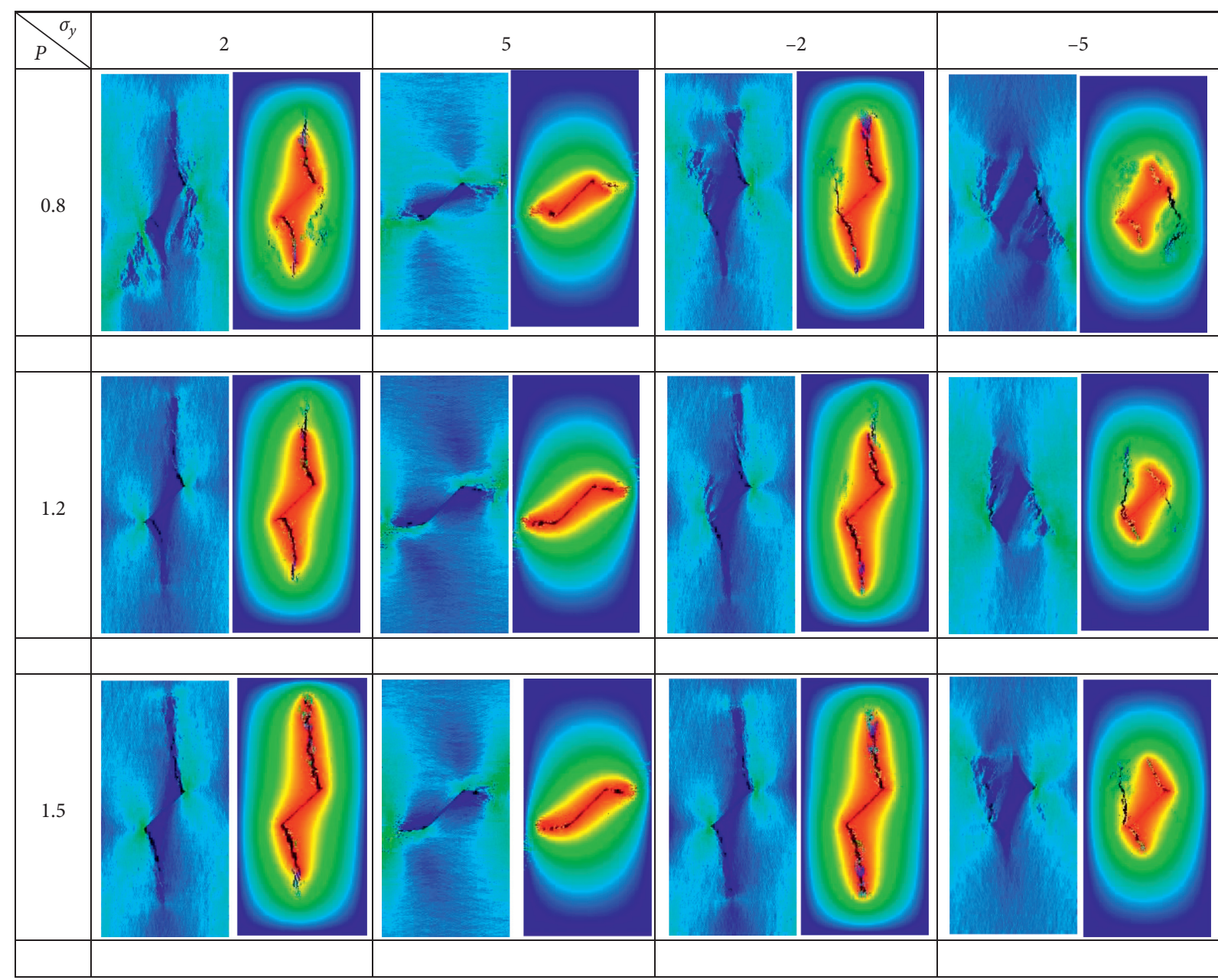

Figure 6: Evolution of shear stress and pore water pressure under confining compression and confining tension. A case of $45^{\circ}$ : (a) confining compression; (b) confining tension.

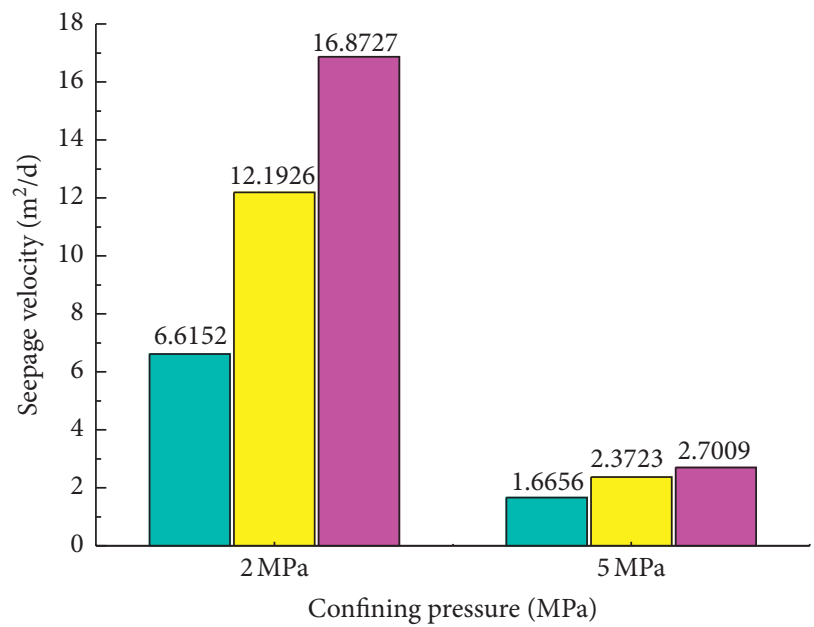

$P=0.8 \mathrm{MPa}$

$\square P=1.2 \mathrm{MPa}$

$\square P=1.5 \mathrm{MPa}$

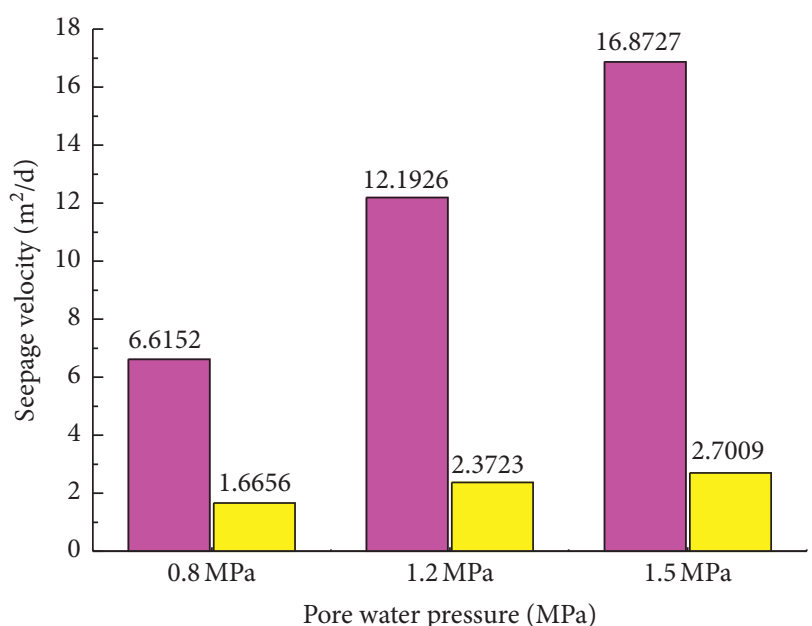

$\sigma=2 \mathrm{MPa}$ $\sigma=5 \mathrm{MPa}$

FIGURE 7: Effects of different factors on axial seepage velocity of cracked specimens: (a) cases with constant confining pressure; (b) cases with constant water pressure. 


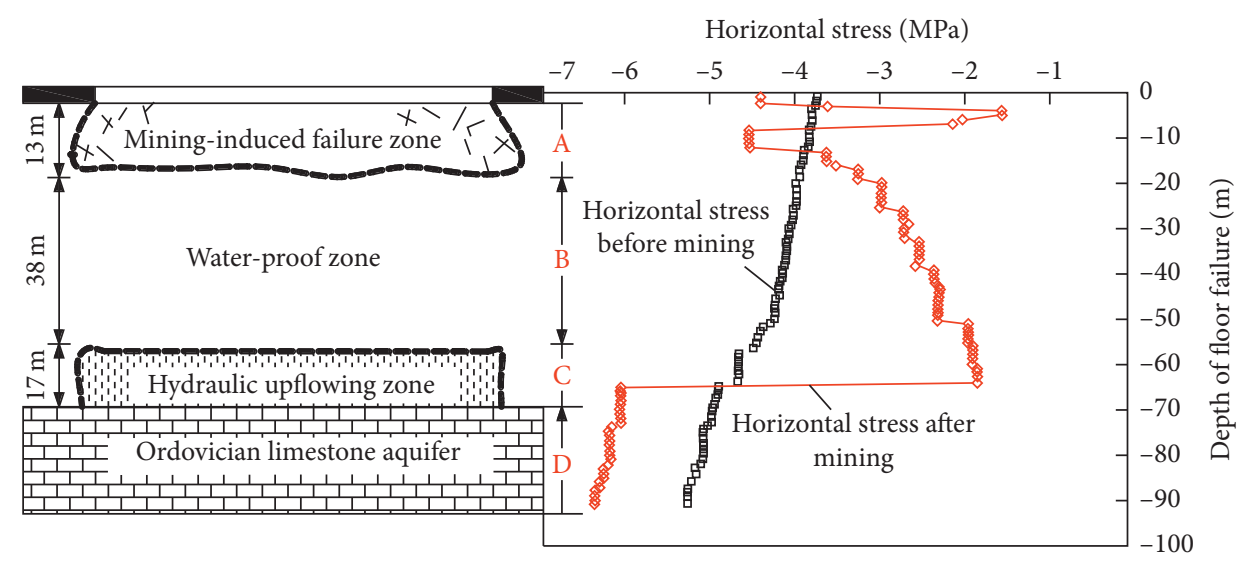

(a)

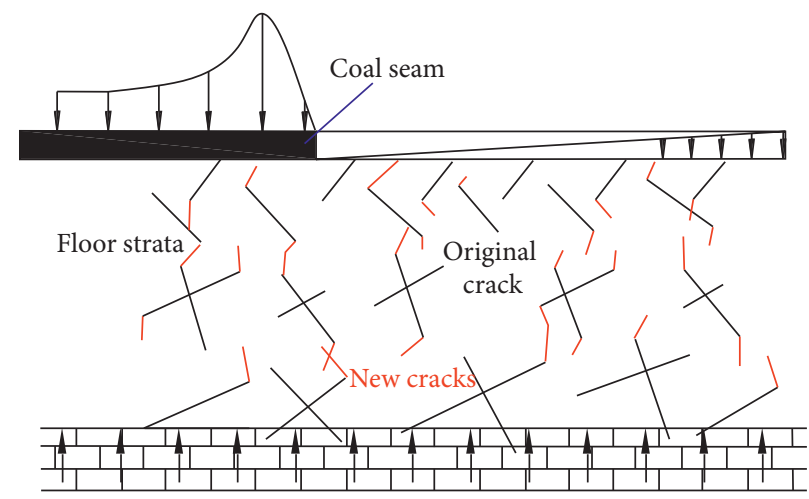

(b)

Figure 8: Failure characteristics and the horizontal stress distribution of floor after mining: (a) characteristic zoning of floor failure and horizontal stress after mining; (b) crack propagation in the rock mass.

layer is directly affected by the pore water pressure in the Ordovician water barrier layer below, and the rock mass develops a vertical crack due to the wedge splitting action of the water pressure. Furthermore, Ordovician water seeps upwards along the vertical crack with low horizontal confining pressure. When the effective water barrier layer reaches a higher confining pressure, the residual water head is unable to rise further and finally stops. The results show that the permeability of the floor rock layer is closely related to the horizontal stress. The conclusions obtained by the simulation explain the phenomenon that the cracks in the confined water lift zone propagate upward in order to form a water inrush channel. On condition that the water pressure is constant, the axial permeability increases with the decrease of the confining pressure (horizontal stress). The cracks in the main rock mass develop into the longitudinal wing crack due to the action of low confining pressure. Thereby, it causes longitudinal permeability to increase.

\section{Conclusions}

A mechanical model based on the theory of fracture mechanics was built in this paper, and the initiation angles of different types of cracks were derived. The seepage failure characteristics of the prefabricated single-crack model under uniaxial compression, confining pressure compression, and confining pressure tension conditions and the effects of related factors were studied using the RFPA software. The mechanical mechanism of the formation of water inrush channels in the unloading zone of the floor was theoretically analyzed. Based on the study, the following conclusions are obtained. The theoretical initiation angles of wing cracks, secondary coplanar cracks, and secondary inclined antiwing cracks were $70.53^{\circ}, 0^{\circ}$, and $123.8^{\circ}$, respectively, which were similar to the results observed in the simulation. The propagation process of prefabricated crack was divided into four stages, namely, the initial stage, the crack initiation stage, the stable crack propagation stage, and the unstable crack propagation stage. During the analysis, the crack propagation was mainly concentrated at the postpeak stage of the complete stress-strain curve in order to make the peak of seepage velocity lag behind the stress peak. Furthermore, the evolution trend of pore water pressure was found to be similar to the crack propagation trend. When the confining pressure was constant, the rate of crack initiation and propagation to final failure was positively correlated with the internal pore pressure. Moreover, the existence of water pressure facilitated crack propagation but did not change the crack shape. The crack propagation mode was a significant difference under low confining pressure and high confining pressure. When the water pressure was constant, the crack that was initiated and propagated until the final rate of 
failure decreased and then increased with the increase of the confining pressure. This indicated that the existence of the confining pressure inhibited the propagation of the crack within a certain range. However, when the confining pressure exceeded a certain value, it could accelerate or facilitate the propagation of cracks.

The permeability in the floor rock was closely related to the horizontal stress after coal seam mining. Moreover, the longitudinal propagation of wing cracks and the increase in permeability in the confined water lift zone were prone to occur in the low confining pressure zone, which induced the formation of water inrush channels.

Although the research results in this paper can promote the scientific understanding of the permeability characteristics of the cracked specimens, it has certain limitations compared to the actual fracture process of the engineering rock mass. The main reason is that crack propagation is related to many factors. The cracks contained in the underground rock mass are randomly distributed and there might be unproven tectonic stress in the environment.

\section{Data Availability}

The data used to support the findings of this study are included within the article.

\section{Conflicts of Interest}

The authors declare that they have no conflicts of interest.

\section{Acknowledgments}

This research was supported by the National Natural Science Foundation of China (Grant Nos. 51874192 and 41807211), Open Fund of Mine Disaster Prevention and Control Key Laboratory of Ministry of Education (no. MDPC201920), and the SDUST Research Fund (Grant 2018TDJH102).

\section{References}

[1] W. Qiang, F. Shu-Kai, Z. Wan-Fang et al., "Application of the analytic hierarchy process to assessment of water inrush: a case study for the No. 17 coal seam in the sanhejian coal mine, China," Mine Water of the Environment, vol. 32, no. 3, pp. 229-238, 2013.

[2] Y. Tian-Hong and L. Ji-Shan, "A coupled flow-stress-damage model for groundwater outbursts from an underlying aquifer into mining excavations," International Journal of Rock Mechanics \& Mining Ences, vol. 44, no. 1, pp. 87-97, 2007.

[3] L. Yin-Long, Rock Damage Fracture Evolution Model and Water Inrush Mechanism of Coal Seam Floor under Seepage Stress Coupling, China University of mining and technology, Xuzhou, China, 2013.

[4] J.-A. Wang and H. D. Park, "Coal mining above a confined aquifer," International Journal of Rock Mechanics and Mining Sciences, vol. 40, no. 4, pp. 537-551, 2003.

[5] Z. Hou-Quan, Y. Tian-Hong, Z. De-Shen et al., Seepage Field Analysis for Water Burst of Roof on Working Face, Dissertation, Coal Geology \& Exploration, Xi'an, China, 2004.

[6] C. Xu, Y. Jin, T. Chun-An et al., "Experimental and numerical investigation of permeability evolution with damage of sandstone under triaxial compression," Rock Mechanics and Rock Engineering, vol. 50, no. 4, pp. 1529-1549, 2017.

[7] W. Wen-Xue, "Influence of stress recovery on permeability evolution of fractured rock mass induced by mining," Journal of the China Coal Society, vol. 39, no. 6, pp. 1031-1038, 2014.

[8] Z. Wei, "Numerical simulation of rock permeability evolution based on improved fluid solid coupling algorithm of particle flow," Journal of Central South University, vol. 25, no. 6, pp. 1367-1385, 2018.

[9] L. Bu, H. Run-Qiu, and W. Li-Zhou, "Study on I-II compression shear composite mode fracture criterion for rock like brittle materials with non-closed cracks," Journal of Geotechnical Engineering, vol. 39, no. 4, pp. 662-668, 2017.

[10] G. Sai-Hong, C. Ping, and W. Sheng-Lian, "Fracture criteria for mode I and II cracks in rocks under water pressure," Journal of Central South University (Natural Science), vol. 43, no. 3, pp. 1087-1091, 2012.

[11] W. F. Brace and E. G. Bombolakis, "A note on brittle crack growth in compression," Journal of Geophysical Research, vol. 68, no. 12, pp. 3709-3713, 1963.

[12] L. Zheng-Zhao, Analysis of Rock Fracture Process under ThreeDimensional Condition and its Numerical Test Method, Dissertation, Northeastern University, Boston, MA, USA, 2005.

[13] L. Yin-Long and W. Lian-Guo, "Numerical simulation of damage fracture and seepage evolution process of coal seam floor based on microcrack evolution," Journal of Mining and Safety Engineering, vol. 32, no. 6, pp. 889-897, 2015.

[14] Z. Pei-Sen, Z. Cheng-Ye, J. Hou-Qun et al., "Experimental study on seepage characteristics of deep sandstone under temperature-stress-seepage coupling conditions," Chinese Journal of Rock Mechanics and Engineering, vol. 39, Article ID 0229, 2020.

[15] S. Wen-Bin, X. Yan-Chao, Y. Li-Ming et al., "Experimental study on seepage characteristics of large size rock specimens under three-dimensional stress," Geomechanics and Engineering, vol. 18, no. 6, pp. 567-574, 2019.

[16] Z. Pei-Sen, J. Hou-Qun, Z. Cheng-Ye et al., "Experimental study on seepage characteristics of red sandstone with different confining pressure and different damage degree," Chinese Journal of Rock Mechanics and Engineering, vol. 39, Article ID 0266, 2020.

[17] A. K. M. B. Alam, M. Niioka, Y. Fujii, D. Fukuda, and J.-i. Kodama, "Effects of confining pressure on the permeability of three rock types under compression," International Journal of Rock Mechanics and Mining Sciences, vol. 65, pp. 49-61, 2014.

[18] Z. Shi-Chuan, G. Wei-Jia, L. Yang-Yang et al., "Experimental simulation of fault water inrush channel evolution in a coal mine floor," Mine Water Environ, vol. 36, no. 3, pp. 443-451, 2017.

[19] S. Wen-Bin, D. Hou-Qian, S. Jian-Li et al., "Numerical analysis of crack propagation evolution of specimens with different dip angles of cross fractures," Geotechnical and Geological Engineering, vol. 37, 2019.

[20] E. Z. Lajtai, "Brittle fracture in compression," International Journal of Fracture, vol. 10, no. 4, pp. 525-536, 1974.

[21] J. Li, C. Chen, S. Wen-Bin et al., "Numerical simulation of the non-Darcy flow based on random fractal micronetwork model for low permeability sandstone gas reservoirs," Geofluids, vol. 2020, no. 6, 9 pages, Article ID 8884885, 2020.

[22] S. Wen-Cheng, "Theoretical analysis and experimental study on failure characteristics and stability of stope floor," Chinese Journal of Rock Mechanics and Engineering, vol. 38, no. 11, pp. 2208-2218, 2019. 
[23] S. Wen-Cheng, L. Zheng-Zhao, and Z. Chun-Bo, "Mechanical failure characteristics of inclined floor along working face in mining above confined water," Chinese Journal of Rock Mechanics and Engineering, vol. 37, no. 9, pp. 2131-2143, 2018.

[24] S. Jian-Jun and L. Wei-Tao, "Discussion on fracture mechanics mechanism of water inrush channel formation in coal seam mining floor," Coal Engineering, vol. 48pp. 128-130, z1, 2016.

[25] F. Bin, H. Li-Hua, and T. Chun-An, "Experimental and numerical investigations on crack development and mechanical behavior of marble under uniaxial cyclic loading compression," International Journal of Rock Mechanics and Mining Sciences, vol. 130, Article ID 104289, 2020.

[26] Z. Yong, Y. Tian-Hong, Z. Peng-Hai et al., "Method for generating a discrete fracture network from microseismic data and its application in analyzing the permeability of rock masses: a case study," Rock Mechanics and Rock Engineering, vol. 52, 2019.

[27] C. A. Tang, H. Liu, P. K. K. Lee, Y. Tsui, and L. G. Tham, "Numerical studies of the influence of microstructure on rock failure in uniaxial compression-Part I: effect of heterogeneity," International Journal of Rock Mechanics \& Mining Ences, vol. 37, no. 4, pp. 555-569, 2000.

[28] F. Erdogan and G. C. Sih, "On the crack extension in plates under plane loading and transverse shear," Journal of Basic Engineering, vol. 85, no. 4, pp. 519-525, 1963.

[29] L. Zheng-Zhao, S. Wen-Cheng, and L. Wei-Tao, "Theoretical models for simulating the failure range and stability of inclined floor strata induced by mining and hydraulic pressure," International Journal of Rock Mechanics and Mining Sciences, vol. 132, Article ID 104382, 2020.

[30] L. Wei-Tao and S. Jian-Jun, "Experimental study of propagation mode of crack in real rock specimens with a single crack," Chinese Journal of Rock Mechanics and Engineering, vol. 35, no. 6, pp. 1182-1189, 2016.

[31] S. Ming-Rong and C. Jian-Feng, Rock Mass Mechanics, Tongji University Press, Tongji, China, 2015.

[32] L. Lian-Chong, Y. Tian-Hong, L. Zheng-Zhao et al., "Numerical investigation of groundwater outbursts near faults in underground coal mines," International Journal of Coal Geology, vol. 85, no. 3-4, pp. 276-288, 2011.

[33] L. Bai-Ying, "The theory of "lower three zones" to prevent water inrush from floor and its development and application," Journal of Shandong Institute of Mining and Technology (Natural Science), vol. 18, no. 4, pp. 11-18, 1999.

[34] W. Jin-An, W. Xian-Hao, and C. Shao-Jie, "Fracture and seepage characteristics of floor rock in confined water," Journal of China University of Mining \& Technology, vol. 4, pp. 536-542, 2012. 